Jurnal Pengajian Melayu - JOMAS, Jilid 32(1), 2021: 89-104

\title{
TRADISI MERANTAU MASYARAKAT MELAYU MENERUSI TEKS TERPILIH KARYA HAMKA
}

\author{
(THE NOMADIC TRADITION OF THE MALAYS \\ IN SELECTED HAMKA TEXTS)

\section{Nurul Aina Ibrahim} \\ nurulainaibrahim@gmail.com
}

\section{Siti Nuranis Muhammad Apandi \\ sitinuranis1988@gmail.com}

Universiti Malaysia Kelantan, Kota Bharu

Malaysia

Received: 3 Februari 2020; Accepted: 8 April 2021

\begin{abstract}
As recorded in selected texts written by Buya Hamka, the nomadic tradition of the Malays is loaded with culture and custom elements. The use of selected texts, namely 'Merantau Ke Deli' and 'Di Bawah Lindungan Ka'bah', was appropriate for the study. This paper also differs from other research due to applying a Western theory to a localised topic such as the Malays'nomadic tradition. Overall, this study aimed to identify the nomadic tradition by the Malays through specific Hamka works and analysed factors that triggered that phenomenon by applying the theory of migration or the 'Push and Pull' Theory introduced by Everett S. Lee (1966). The researchers utilised a qualitative approach, strengthened by Lee's theory. The theory suggests four factors factors found within the place of origin, factors in the destination, obstacles and other personal factors. The study found that the Malay characters in Hamka's works travelled to leave their origin due to poverty and gender issues. Factors at the destination were the promise of a more comfortable life and receiving higher education. It is hoped that this paper could be beneficial and used by researchers in future.
\end{abstract}

Keywords: nomadic tradition, the Malay community, factors, concepts, Theory of Migration by Everett S. Lee. 


\begin{abstract}
Abstrak
Tradisi merantau masyarakat Melayu menerusi teks terpilih Hamka ini sememangnya sarat dengan nilai budaya dan adat resam orang Melayu. Di samping itu, penggunaan teks terpilih, iaitu Merantau Ke Deli dan Di Bawah Lindungan Ka'bah bersesuaian dengan tajuk kajian. Kajian ini berlainan dengan kajian yang pernah ada di dunia penyelidikan Malaysia kerana teori Barat diterapkan bersama tajuk tempatan, iaitu tradisi merantau yang diamalkan oleh masyarakat Melayu. Kajian ini bertujuan untuk mengenal pasti tradisi merantau oleh masyarakat Melayu dalam teks terpilih karya Buya Hamka. Kajian ini juga bertujuan menganalisis faktor tradisi merantau terhadap masyarakat Melayu menerusi teks terpilih hasil karya Buya Hamka dengan mengaplikasikan Teori Migrasi (Push and Pull Theory) yang dipelopori oleh Everett S Lee (1966). Pendekatan kajian yang digunakan ialah kualitatif bagi menyempurnakan kajian ini. Kajian ini juga menggunakan Teori Migrasi Everett S. Lee bagi mengukuhkan lagi kajian ini. Teori ini yang terdiri daripada empat faktor, iaitu faktor yang terdapat di tempat asal, faktor yang terdapat di tempat tujuan, rintangan yang menghalang dan faktor peribadi. Hasil kajian mendapati konsep tradisi merantau masyarakat Melayu berdasarkan teks terpilih adalah meninggalkan tempat asal, manakala faktor tradisi merantau yang terdapat di tempat asal ialah kerana kemiskinan dan jenis jantina dan faktor yang terdapat di tempat tujuan pula kehidupan yang selesa serta tingkat pendidikan. Oleh itu, diharapkan kajian ini boleh memberi manfaat dan diguna pakai oleh pengkaji pada masa akan datang sebagai rujukan kepada penyelidikan.
\end{abstract}

Kata Kunci: tradisi merantau, masyarakat Melayu, faktor, konsep, Teori Migrasi Everett S. Lee.

\title{
Pengenalan
}

Tradisi merantau merupakan satu aktiviti yang menggunakan semangat dan aktiviti yang jitu bagi membina sebuah kehidupan agar memberikan petunjuk pada masa akan datang. Perkataan dan istilah merantau adalah dari Indonesia yang bermaksud belayar mencari kehidupan di sepanjang rantau dari sungai ke sungai yang lain (Kamus Bahasa Indonesia Online, 2011). Tradisi ini dilihat istimewa dalam budaya Melayu kerana fungsi dan cirinya yang tersendiri.

Di samping itu, merantau pula menurut Tsuyoshi (1989, p. 12) bermaksud meninggalkan kampung halaman atau negeri asal. Hal ini kerana, dapat dilihat menerusi pemikiran masyarakat Melayu terhadap merantau yang seringkali dikaitkan dengan kepercayaan kepada agama Islam yang kuat. Namun begitu, istilah merantau dari perspektif masyarakat Minangkabau agak berbeza, iaitu merantau merupakan satu aktiviti keluar dari negeri atas tujuan mencari kekayaan, ilmu atau kemasyhuran (Tsuyoshi, 1989, p. 4).

Menurut penelitian yang dilakukan oleh Mochtar Naim (2013, p. 181) mendapati generasi muda merupakan generasi yang paling ramai merantau. Lazimnya, para perantau akan menamatkan sekolah menengah terlebih dahulu. Di samping itu, kebanyakan masyarakat Minangkabau akan pergi merantau sebelum mereka mendirikan rumah tangga atau berkahwin. Hal ini kerana, menurut orang Minang, merantau merupakan satu pendidikan informal yang harus dilalui bagi orang muda sebelum mereka berkahwin. 
Namun begitu, tradisi merantau merupakan satu faktor yang meningkatkan imej, status, taraf sosial dan juga ekonomi individu mahupun masyarakat (Khazrin 2001, p. 74). Justeru, anakanak lelaki dalam masyarakat Melayu sudah diberi motivasi untuk merantau sejak dari kecil lagi, tambahan pula pada zaman itu, pendidikan hanya ditumpukan kepada kecerdasan emosi serta fizikal berbanding kecerdasan intelek. Antara ilmu yang dipelajari ialah ilmu seni mempertahankan diri dan keagamaan sebagai satu persediaan untuk keluar merantau. Pada masa itu, masyarakat Minangkabau berpegang kepada prinsip untuk tidak membawa apa-apa bekalan mahupun modal semasa keluar merantau tetapi harus menggunakan ilmu yang dipelajari (Afif \& Savaria, 2008).

Oleh itu, kajian ini akan memperincikan tradisi merantau dalam masyarakat Melayu menerusi teks terpilih, iaitu Merantau Ke Deli dan Di Bawah Lindungan Ka'bah hasil karya Buya Hamka yang amat kaya dengan nilai-nilai murni dan adat Minang. Akhir sekali, kajian ini juga menelusuri penggunaan teori barat sebagai satu garis panduan kepada kajian ini, iaitu Teori Migrasi (Push and Pull Theory) yang dipelopori oleh Everett S. Lee (1966). Teori ini terdiri daripada empat faktor utama, iaitu faktor yang terdapat di tempat asal atau dikenali sebagai faktor penolak, faktor yang terdapat di tempat tujuan atau dikenali sebagai faktor penarik, rintangan yang menghalang serta faktor peribadi. Namun begitu, dalam kajian ini hanya menggunakan dua faktor daripada empat faktor ini, iaitu faktor yang terdapat di tempat asal (Faktor Penolak) dan faktor yang terdapat di tempat tujuan (Faktor Penarik).

\section{Penyataan Masalah}

Kajian ini memperincikan mengenai tradisi merantau yang seringkali menjadi satu aktiviti yang popular dalam masyarakat Melayu sejak dahulu lagi menerusi karya Hamka yang terpilih. Oleh itu, kajian ini dimulakan kerana tiada banyak kajian yang memilih topik migrasi atau merantau terutama dalam penggunaan teori barat. Namun begitu, sejak beberapa tahun ini, para pengkaji sastera memilih untuk mengkaji tajuk kajian mengenai merantau namun terdapat kekurangan dan kekangan seperti bahan kajian yang terhad. Hal ini merujuk kepada sebuah kajian daripada Azri Shaharudin (1996, p. 8) menerusi kajian bertajuk "Merantau: Pola Migrasi Imigran Indonesia Keturunan Minangkabau ke Malaysia" yang menyebut mengenai "ketiadaan kajian-kajian terdahulu khususnya dalam bidang ini, sedikit sebanyak akan mendatangkan kesan negatif kepada kajian yang diusahakan oleh pengkaji. Hal ini kerana, kekangan bahan rujukan seperti tesis, artikel atau jurnal daripada para sarjana sebagai sokongan kepada penulisan ilmiah pada masa akan datang.

Selain itu, teks-teks sastera juga kurang mendapat sambutan para pembaca yang kebanyakan mereka hanya lebih mengutamakan pembacaan ringan sahaja seperti buku Indie yang telah muncul dalam dunia penulisan seiring dengan perkembangan teknologi (Fadli \& Md Sidin, 2016). Hal ini kerana, pembacaan ringan seperti novel-novel picisan lebih mudah difahami tanpa berfikir dengan begitu mendalam ketika melakukan pembacaan. Namun begitu, teks-teks sastera yang berkualiti tinggi seperti karya Hamka sering dipandang sepi oleh pembaca kerana memerlukan kefahaman yang tinggi. Hal ini disokong oleh Othman Puteh (1998, p. 10-11) yang menyatakan bahawa sastera remaja harus mempunyai keupayaan bagi mengasah dan mengasuh kecerdasan penghayatan menerusi nilai-nilai kemanusiaan, kemasyarakatan serta segala yang berhubungan dengan kehidupan manusia. 
Oleh itu, kajian ini akan mengisi kelompongan dalam dunia sastera mengenai tajuk kajian, iaitu tradisi merantau masyarakat Melayu dalam teks terpilih menerusi hasil karya Hamka. Teks ini juga merupakan satu teks agung yang seringkali dijadikan bahan kajian oleh para ahli akademik. Selain itu, Merantau Ke Deli dan Di Bawah Lindungan Ka'bah juga merupakan karya sastera yang telah berjaya memaparkan gaya dan konsep tradisi merantau masyarakat Melayu pada ketika itu. Kajian mengenai tradisi merantau pernah dilaksanakan oleh Faezah Kassim dan Norazalan Hadi Yaacob (2018), iaitu 'Tradisi Merantau dalam Masyarakat Melayu dalam Puisi Tradisional' tetapi bidang atau fokus kajian tersebut berlainan daripada kajian-kajian lain. Justeru, selain ingin mengisi kelompongan dalam kajian-kajian sastera sedia ada, kajian ini turut dapat menjadi panduan dan rujukan kepada pengkaji-pengkaji lain pada masa akan datang.

\section{Objektif Kajian}

Kajian yang dijalankan ini berusaha bagi menjawab persoalan-persoalan berdasarkan dua objektif berikut:

i. Mengenal pasti konsep tradisi merantau oleh masyarakat Melayu dalam teks terpilih karya Hamka.

ii. Menganalisis faktor tradisi merantau terhadap masyarakat Melayu menerusi teks terpilih karya Hamka dengan mengaplikasikan Teori Migrasi (Push and Pull Theory) yang dipelopori Everett S. Lee (1966).

\section{Persoalan Kajian}

Persoalan-persoalan yang menjadi perhatian pengkaji dalam melakukan kajian ini ialah:

i. Apakah konsep tradisi merantau oleh masyarakat Melayu menerusi teks terpilih karya Hamka?

ii. Bagaimanakah faktor tradisi merantau terhadap masyarakat Melayu menerusi teks terpilih karya Hamka dengan mengaplikasikan Teori Migrasi (Push and Pull Theory) yang dipelopori Everett S. Lee (1966).

\section{Batasan Kajian}

Kajian ini membataskan dua buah novel terpilih hasil karya Hamka sebagai bahan kajian. Kedua-dua novel ini bersesuaian dengan pengaplikasian Teori Migrasi (Push and Pull Theory) yang dipelopori oleh Everett S. Lee (1966). Sehubungan itu, dua buah novel karya Hamka telah dijadikan bahan kajian, iaitu Di Bawah Lindungan Ka'bah (2015) dan Merantau Ke Deli (2015). Kedua-dua buah novel tersebut diterbitkan oleh Publishing House Sendirian Berhad. Kajian ini hanya membincangkan faktor yang terdapat di tempat asal (Push Factors) dan faktor yang terdapat di tempat tujuan (Pull Factors). 


\section{Sorotan Kajian}

Sebuah kajian yang dihasilkan oleh Pardi (2019) dari Fakulti Sastera, Universiti Islam Sumatera Utara yang bertajuk "Citra Perempuan Jawa dalam Novel Merantau Ke Deli Karya Hamka” bertujuan untuk menganalisis citra perempuan Jawa menerusi novel Merantau Ke Deli karya Hamka. Kajian ini juga telah menggunakan Teori Kritik Sastera Feminisme yang bersesuaian dengan citra wanita dalam menghuraikan pengetahuan dan pengalaman mengenai konsep feminisme. Kaedah kualitatif digunakan dalam proses analisis citra perempuan Jawa dalam novel Merantau Ke Deli karya Hamka. Hasil kajian pengkaji mendapati perempuan Jawa memiliki sembilan ciri, iaitu setia kepada lelaki, rela dimadu, mencintai satu sama lain, trampil pada pekerjaan perempuan, pandai berdandan dan lain-lain lagi.

Di samping itu, kajian sarjana pendidikan oleh Annisa Septia (2016) yang bertajuk "Dinamika Kepribadian Tokoh Utama Dalam Roman Di Bawah Lindungan Ka'bah Karanagan Hamka dengan Senario Filem Di Bawah Lindungan Ka 'bah Karya Titien Wattimena dan Armantono (Suatu Kajian Psikologi Sastera) " bertujuan untuk mengetahui dinamika keperibadian, ekranisasi, sastera bandingan, psikologi sastera dan pembelajaran bahasa dan sastera di sekolah. Kaedah deskriptif kualitatif diguna pakai bersama dengan teori dinamika keperibadian. Hasil penelitian menunjukkan tokoh utama roman Di Bawah Lindungan Ka'bah yang mempunyai dinamika keperibadian, iaitu naluri kehidupan serta kematian.

Selain itu, sebuah kajian yang bertajuk "Hubungan Migrasi Dalaman dengan FaktorFaktor Penarik: Kajian Kes di Malaysia" yang ditulis oleh Nor Ermawati Hussain, Norehan Abdullah, \& Hussin Abdullah (2015) dalam Jurnal Ekonomi Malaysia, Universiti Utara Malaysia telah membincangkan mengenai perpindahan atau penghijrahan migrasi keluar masuk ke kawasan destinasi adalah merupakan faktor utama kepada penyumbang pertumbuhan ekonomi bagi sesebuah negeri. Di samping itu, kajian ini memperincikan mengenai objektif kajian, iaitu melihat pengaruh faktor-faktor makro dalam menyumbang kesan kepada migrasi masuk bagi beberapa kawasan utama di Malaysia. Kajian ini menggunakan beberapa teori, antaranya ialah Teori Migrasi yang kemudian dikembangkan menjadi Teori Neoklasik, Teori Membuat Keputusan Lee, dan Teori Zelinky. Kaedah data panel digunakan yang berbentuk tahunan serta melibatkan kawasan utama di Malaysia, iaitu hanya enam buah negeri sahaja yang terlibat. Kajian tersebut telah memberi hasil mengenai hubungan jangka panjang yang positif di antara pembolehubah migrasi masuk dengan pelaburan domestik bagi beberapa negeri.

Seterusnya, sebuah penulisan yang dilakukan oleh Akbar (2019), dari Fakulti Ilmu Budaya Universiti Andalas, Padang, Indonesia yang bertajuk "Perspektif Merantau Dalam Novel Dijemput Mamaknya Karya Hamka (Tinjauan Sosiologi Sastera)” adalah untuk meneliti bentuk realiti sosial masyarakat Minangkabau mengenai merantau serta menjelaskan bentuk realiti sosial merantau yang terdapat dalam novel Dijemput Mamaknya. Selain itu, kajian ini juga menggunakan metode dialektik yang banyak mengembangkan konsep pemahaman-pemahaman mengenai objek, aspek-aspek serta struktur-struktur pembangunan objek penelitian dan kemahuan akan dianalisis dengan meninjau sosiologi sastera. Kajian ini juga berlandaskan teori sosiologi sastera. Kajian ini memberi hasil kajian perspektif merantau dalam novel Dijemput Mamaknya yang memberi refleksi akan pandangan pengarang. 
Di samping itu, Marlina (2018), dari Balai Bahasa Riau, Kampus Universitas Riau menerusi Jurnal yang bertajuk “Tradisi Merantau Masyarakat dalam 'Lelaki dan Tangkai Sapu'” telah mengkaji budaya merantau menerusi puisi 'Lelaki dan Tangkai Sapu' karya Iyut Fitra. Artikel ini juga turut membincangkan mengenai aktiviti merantau yang merupakan satu usaha bagi menjalani kehidupan yang penuh ragam, pengalaman, dan keluasan ilmu pengetahuan untuk mencapai sesuatu kejayaan. Kajian ini menggunakan pendekatan Sosiologi Sastera bagi mencapai objektif kajian. Selain itu, kajian ini turut menggunakan pendekatan kualitatif dalam pengumpulan data, pengolahan dan analisis data. Hasil kajian ini menyimpulkan bahawa budaya merantau merupakan satu pengusiran kepada kaum lelaki dan mengikut pengkaji merantau adalah satu pemaksaan kepada kaum tersebut.

Seterusnya, sebuah jurnal daripada Agatha Trisari S \& Hanny Harashani (2018) yang bertajuk "Tradisi Merantau dalam cerita Rakyat Sunda Nyi Mas Kanti" dari Fakulti Sosial Ilmu dan Budaya Universiti Pakuan, Bogor, Indonesia bertujuan untuk mengkaji cerita rakyat Nyi Mas Kanti dengan menggunakan strukturalisme naratif Levi-Strauss dan menganalisis pola merantau yang terdapat dalam cerita rakyat. Di samping itu juga, artikel ini menggunakan Teori Strukturalisme Naratologi Levi-Strauss sebagai panduan yang diambil pustaka teori yang relevan bagi kajian sastera lisan dalam ilmu sastera ini. Hasil kajian yang terdapat dalam artikel ini adalah tradisi merantau dalam Cerita Rakyat Nyi Mas Kanti, iaitu skema pergerakan perpindahan menerusi cerita rakyat ini adalah berdasarkan kriteria merantau seperti meninggalkan kampung halaman, pergi dengan terpaksa, untuk jangka masa yang lama atau tidak, kebiasaannya dengan membawa maksud akan kembali pulang. Oleh yang demikian, jelaslah kajian ini adalah berbeza dengan aspek yang ingin dikaji dalam kajian ini, iaitu mengenai tradisi merantau.

Rizki Muhadi (2019) dari Fakulti Ilmu Budaya Universiti Andalas, Padang, Indonesia telah menghasilkan tesis yang bertajuk "Mantra Baka Bajalan dalam Tradisi Merantau Orang Minangkabau. Kajian tersebut mempunyai dua objektif kajian, iaitu mengumpulkan mantramantra baka bajalan bagi masyarakat Minangkabau terutama di daerah Pasaman Barat, Sijunjung, dan Pesisir Selatan serta menjelaskan struktur mantra baka bajalan bagi masyarakat Minangkabau terutama yang ditemukan di daerah Pasaman Barat, Sijunjung, dan Persisir Selatan. Kajian ini berlandaskan Teori Struktur Puisi yang akan menganalisis mantra ini yang merupakan puisi yang terdiri daripada struktur-struktur pembangun seperti irama, rima, penyusunan lirik dan bait yang penuh dengan makna yang tersendiri. Oleh yang demikian, menerusi pendekatan struktur puisi, penulis dapat menganalisis mantra baka bajalan yang juga milik masyarakat serta fungsi mantra bagi masyarakat Minangkabau semasa merantau serta mampu menjelaskan penerapan mantra baka bajalan sendiri daripada ritual-ritual, media, alat atau bahan untuk komunikasi dengan menggunakan mantra dalam sesebuah kehidupan masyarakat Minangkabau. Di samping itu, kajian ini juga menggunakan kaedah kualitatif yang terdiri daripada teknik pengumpulan data, analisis data, dan penyajian hasil analisis data. Di samping itu, mantra ini juga dianalisis dengan menggunakan teori struktur puisi yang terdiri daripada dunia fizik dan struktur batin yang mampu menonjolkan tradisi merantau orang Minangkabau yang bergantung kepada mantra baka bajalan.

Seterusnya, Satria Handika Fuadi (2019), telah melakukan kajian bagi mengikut syarat untuk memperoleh gelaran sarjana jurusan Sastera Minangkabau dari Fakulti Ilmu Budaya Universiti Andalas, Padang, Indonesia. Tajuk kajian beliau ialah "Perkahwinan Beda Etnis Dalam Novel Merantau Ke Deli Karya Hamka (Pendekatan Sosiologi Sastra)" yang bertujuan menjelaskan 
bentuk perkahwinan dalam etnik Minangkabau dan etnik Jawa. Ternyata jelas dapat dilihat perkahwinan antara etnik Minangkabau dan etnik Jawa berlaku dalam novel Merantau Ke Deli. Di samping itu, dari sudut teknik penelitian adalah dari segi teknik penyediaan data, teknik analisis data, dan teknik penyajian hasil analisis. Seterusnya, dari sudut penggunaan landasan teori pula telah menggunakan pendekatan sosiologi sastera. Di samping itu, hasil kajian menunjukkan watak Leman tidak berkahwin dengan wanita yang sama etnik tidak semestinya boleh menghasilkan satu keharmonian, namun perbezaan perkahwinan etnik ini boleh mencipta konflik kerana wujudnya perbezaan latar sosial dan budaya.

Berdasarkan kajian-kajian lepas, ternyata pelbagai isu, tajuk, teori, objektif, dan bahan kajian telah dilakukan oleh para pengkaji terdahulu dalam kajian masing-masing. Pengkaji juga telah menyorot pelbagai jenis kajian, iaitu artikel, tesis, mahupun jurnal-jurnal mengenai kata-kata kunci yang penting bagi mengukuhkan lagi kajian ini. Oleh itu, kajian yang bertajuk "Tradisi Merantau Masyarakat Melayu Menerusi Karya Terpilih Hamka” ini diharap dapat membantu para pengkaji lain untuk melakukan kajian mereka dengan menggunakan pelbagai teori, fokus, dan bahan-bahan kajian yang berbeza.

\section{Metodologi Kajian}

Metodologi kajian ini meliputi cara, kaedah dan pendekatan yang digunakan untuk mencapai objektif kajian, iaitu penelitian deskriptif kualitatif. Kaedah ini dilaksanakan menerusi teknik analisis seperti bacaan (memoing) yang juga merupakan satu teknik menerusi pembacaan kepada novel kajian. Kaedah ini bertujuan memastikan data-data seperti konsep, dan faktor tradisi merantau masyarakat Melayu yang terdapat dalam teks kajian dapat dikenal pasti setelah teknik bacaan dilakukan oleh pengkaji. Seterusnya, pengkaji menggunakan teknik penerangan yang merupakan satu cara untuk menjelaskan konsep dan faktor tradisi merantau masyarakat Melayu. Seterusnya, kaedah pengelasan yang merupakan satu cara untuk mengumpulkan data-data kepada unit-unit kecil berdasarkan tema-tema dalam kategori tersendiri turut diaplikasikan dalam kajian ini. Teknik akhir yang dimanfaatkan oleh pengkaji dalam kajian ini ialah teknik pentafsiran, iaitu setelah teknik pembacaan, penerangan dan pengelasan dilakukan. Oleh itu, ketiadaan skala pengukuran dalam kajian teks juga telah menggantikan dengan kaedah yang diukur dengan sumber-sumber data, iaitu menerusi kata-kata, frasa, ayat, ungkapan yang terdapat dalam teks kajian. Sumber data utama ialah teks pilihan hasil karya Hamka, iaitu Di Bawah Lindungan Ka'bah dan Merantau Ke Deli.

Kajian ini juga mengaplikasikan penggunaan teori barat daripada Everett S. Lee (1966), iaitu Teori Migrasi yang terdiri daripada empat faktor. Faktor-faktor tersebut ialah faktor yang terdapat di daerah asal (Push Factor), faktor yang terdapat di tempat tujuan (Pull Factor), rintangan yang menghambat, dan faktor peribadi. 


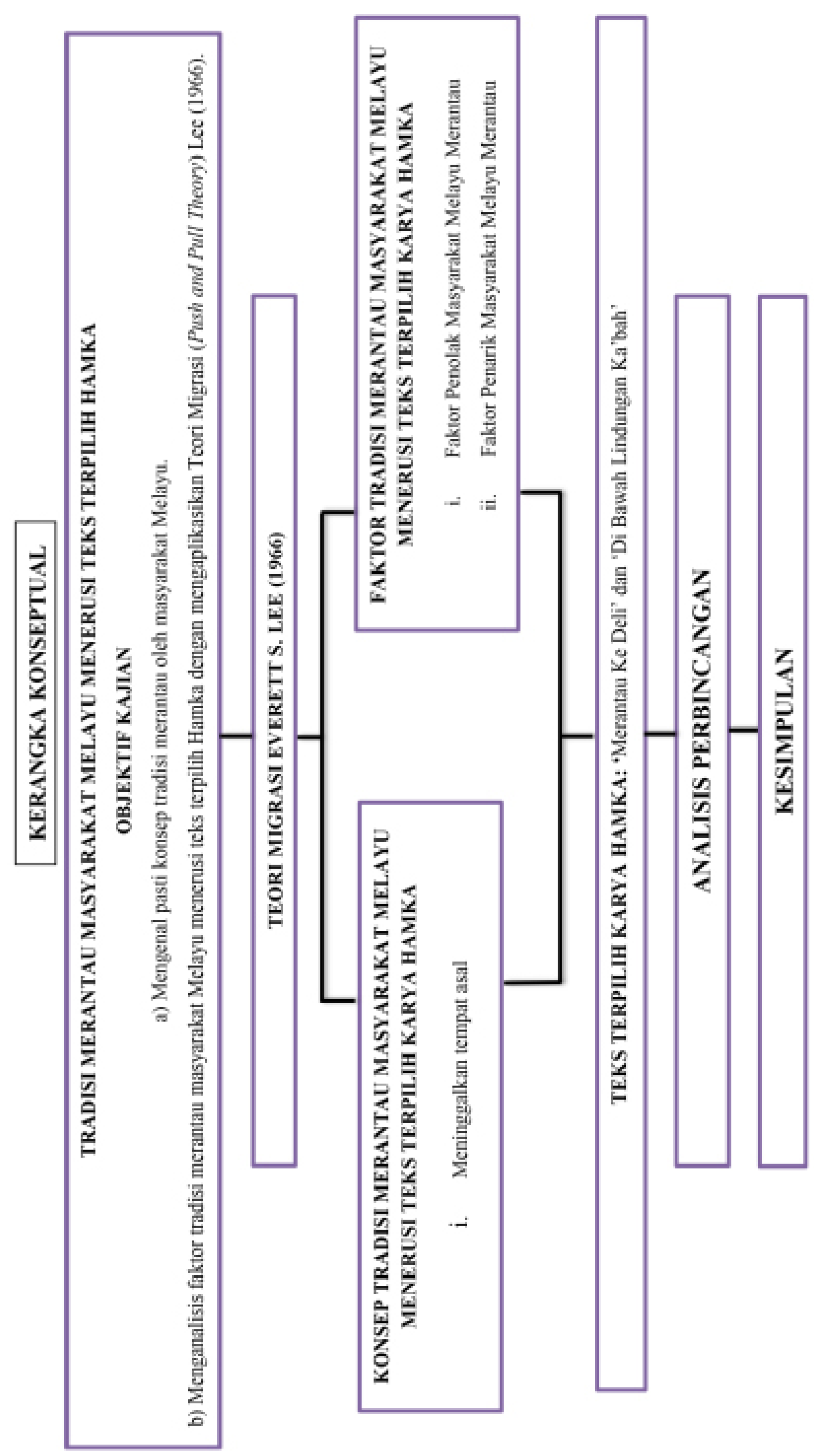




\section{APLIKASI TEORI MIGRASI EVERETT S. LEE (1966)}

Teori Migrasi Everett S. Lee (1966) merupakan teori barat yang diterbitkan dalam Demoghraphy Journal. Teori ini merupakan sumbangan idea daripada Raveinstein, iaitu menerusi 'Law of Migration' yang juga merupakan satu pembelajaran mengenai populasi. Teori ini menggunakan prinsip sosiologi sebagai salah satu usaha untuk memberi penerangan mengenai faktor berlakunya sesebuah migrasi berlaku, iaitu sama ada berpunca daripada tempat asal atau dari tempat tujuan migran itu sendiri seperti yang telah dinyatakan oleh Everett S. Lee (1966). Justeru, Everett S. Lee (1966) telah meletakkan konsep terhadap faktor-faktor yang berkaitan dengan migran yang membuat keputusan untuk bermigrasi kepada empat faktor:

1. Faktor yang terdapat di tempat asal.

2. Faktor yang terdapat di tempat tujuan.

3. Rintangan yang menghalang.

4. Faktor peribadi.

Faktor yang terdapat di tempat asal merupakan penyebab seseorang membuat keputusan untuk meninggalkan tempat asal dan berhijrah ke tempat lain. Keadaan tersebut juga dikenali sebagai Push Factors. Di samping itu, faktor yang terdapat di tempat tujuan pula bermaksud daya tarikan yang ada di tempat tujuan yang menyebabkan golongan migran bermigrasi dari tempat asal ke tempat tujuan atas faktor tertentu. Keadaan ini dikenali pula sebagai Pull Factors. Seterusnya, rintangan yang menghalang merupakan segala halangan yang melanda golongan migran semasa dalam proses migrasi. Golongan migran dapat menghadapi halangan tersebut dengan pelbagai cara yang mereka lakukan. Halangan ini termasuklah yang berkaitan dengan jarak dan pengangkutan. Keadaan ini boleh diatasi dengan adanya kepesatan teknologi yang semakin canggih dari hari ke hari. Akhir sekali, faktor peribadi merupakan antara faktor yang berkaitan dengan tempat asal dan tempat tujuan. Persepsi dan pandangan daripada seseorang individu juga mempengaruhi keputusan seseorang untuk bermigrasi sama ada kekal di tempat asal atau pindah ke tempat tujuan. Namun begitu, kajian ini hanya membincangkan faktor yang terdapat di tempat asal (Push Factors) dan faktor yang terdapat di tempat tujuan (Pull Factors).

\section{Analisis Kajian}

Berdasarkan analisis kajian yang dilaksanakan didapati terdapat beberapa konsep dan faktor tradisi merantau masyarakat Melayu menerusi teks terpilih karya Hamka, iaitu Merantau Ke Deli dan Di Bawah Lindungan Ka'bah.

\section{Konsep Tradisi Merantau Masyarakat Melayu dalam Teks Terpilih Karya Hamka Meninggalkan Tempat Asal}

Meninggalkan tempat asal adalah satu perkara yang dilakukan oleh perantau untuk meninggalkan kampung halaman. Hal ini disokong oleh Naim (1984, p. 3) yang menyatakan meninggalkan 
kampung halaman menafsirkan jarak menurut perkembangan waktu. Hal ini kerana, dengan meninggalkan tempat asal akan melahirkan satu keadaan yang baharu kepada perantau untuk lebih bersedia dalam dunia yang mencabar pada masa akan datang. Pelbagai pesanan serta titipan nasihat akan diterima oleh sang perantau dari pelbagai masyarakat sebagai satu persedian untuk keluar merantau. Anak-anak muda yang keluar merantau akan dipesan pelbagai nasihat, petua, dan pantang-larang daripada orang tua-tua terutama daripada dalam keluarga serta jiran tertangga. Kadangkala, keluarga mereka akan melaksanakan kenduri seperti bacaan doa selamat agar perjalanan sang perantau akan dipermudahkan urusan, mudah, selamat dan iman mereka dijaga oleh Sang Pencipta. Di samping itu, ketua keluarga pasti akan memberi ucapan yang berimpak besar kepada si perantau agar menjaga segala pertuturan, berbuat baik kepada orang lain dan sentiasa bersabar menghadapi segala ujian daripada Allah SWT semasa di perantauan (Nazarudin, Rahimah, \& Mohd Kipli, 1985, p. 45).

\section{"Meskipun ketika dia akan meninggalkan kampungnya dahulu telah diberi ingat benar-benar oleh orang tua-tua supaya hati-hati di tanah Deli, supaya ingat bahawasanya laut sakti dan rantau bertuah..."}

(Di Bawah Lindungan Ka'bah, 2015, p. 7)

Petikan di atas jelas menunjukkan watak utama, iaitu Leman yang diberi nasihat oleh keluarganya agar sentiasa menjaga adab, dan mematuhi pantang larang yang ada semasa di perantauan. Walaupun di Deli itu dikatakan sebagai tanah bertuah kepada sang perantau yang mencuba nasib di negeri tersebut, nasihat orang tua tidak harus dilupakan kerana pelbagai ujian dan rintangan pasti wujud kepada seseorang yang ingin berjaya. Hal ini kerana, sejarah menyatakan bahawa Tanah Deli ini merupakan jantung kepada penjajah terutama orang Eropah kerana bumi Deli ini amat kaya dengan perkebunan tembakau. Hal ini sedikit sebanyak telah memajukan ekonomi di tanah Deli hingga boleh digelar sebagai tanah bertuah (Muhammad Takari, A. Zaidan \& Fadlin, 2012, p. 137). Hal ini sejajar dengan penggunaan Teori Migrasi Everett S. Lee yang menyebabkan faktor tradisi merantau masyarakat Melayu dalam teks terpilih ini adalah kerana dorongan daripada keluarga untuk keluar merantau. Hal ini kerana menurut Akmal \& Nurwianti (2012), bahawa orang Minang mempunyai tradisi meninggalkan tanah air mereka kerana menetap di tempat lain yang dianggap sebagai kehidupan yang layak.

\section{Faktor Tradisi Merantau Masyarakat Melayu dalam Teks Terpilih Karya Hamka}

Berdasarkan penelitian terhadap dua karya Hamka, iaitu Merantau Ke Deli dan Di Bawah Lindungan Ka'bah, pengkaji mendapati wujud dua faktor yang menyebabkan tradisi merantau dalam kalangan masyarakat Melayu, iaitu faktor penolak dan faktor penarik.

1. Faktor Penolak Masyarakat Melayu Merantau dalam Teks Terpilih Karya Hamka:

e ISSN 2735 - 1904

https://doi.org/10.22452/JOMAS.vol32no1.6 
a) Jenis jantina

Faktor Penolak menyebabkan masyarakat Melayu ingin berpindah dari tanah asal atau kampung halaman mereka ke suatu tempat yang lain. Oleh itu, terdapat beberapa perkara yang dikatakan sebagai penyebab kepada mereka yang keluar merantau. Menurut Mitchell (1961) dan disokong oleh Mantra (2000), terdapat beberapa kekuatan yang menyebabkan faktor-faktor penduduk terikat di tempat asal kerana tempat asal adalah sebagai sentripetal seperti terikat dengan tanah warisan, menjaga orang tua yang lanjut usia dan adat yang mengikat bahawa tempat asal merupakan tempat kelahiran nenek moyang.

Faktor ini merupakan penyebab kepada seseorang mengambil keputusan untuk berpindah dari tempat asal ke tempat tujuan. Penghijrahan seseorang perantau tidak semestinya disebabkan oleh perkara atau sesuatu yang negatif, namun terdapat juga sebab yang positif bagi seseorang itu merantau atau bermigrasi. Antara faktor masyarakat Melayu pergi merantau ialah faktor jenis jantina. Kaum lelaki lebih berpeluang keluar merantau berbanding dengan kaum perempuan. Hal ini kerana, kaum lelaki mempunyai simbolik kuat, gagah dan khalifah ini sedikit sebanyak menjadi faktor kepada kaum lelaki digalakkan keluar merantau. Merantau bagi orang lelaki merupakan satu inisiatif yang harus dilalui oleh mereka terutama pada usia yang muda kerana dengan aktiviti ini tidak hanya kekayaan dan pengetahuan diperoleh, tetapi juga kebanggaan peribadi bagi seseorang lelaki (Hastuti, Thoyib, Troena \& Setiawan, 2015).

"Saya tidak berapa bulan setelah tamat sekolah, berangkat ke Padang Panjang, melanjutkan cita-cita ibu saya karenan kedermawanan Engku Ja'far juga... Yang berasa sedih amat, adalah anak-anak perempuan yang akan masuk pingitan; tamat sekolah bagi mereka artinya suatu sangkar yang telah tersedia buat seekor burung yang bebas terbang."

(Di Bawah Lindungan Ka'bah, 2015, p. 23)

Oleh itu, jelas menunjukkan penggunaan Teori Migrasi Everett S. Lee (1966) ini adalah bertepatan dengan kajian ini kerana faktor penolak tradisi merantau merupakan satu daripada induk kepada teori ini. Jenis jantina juga merupakan satu daripada faktor kepada aktiviti merantau ini seperti mana yang ditunjukkan dalam petikan di atas, iaitu watak Hamid menyatakan orang perempuan tidak digalakkan keluar merantau untuk menyambung pelajaran seperti orang lelaki. Menurut Dwi Putri Rahmalia, (2020, p. 9), adat yang mengekang perempuan Minangkabau agar kekal di rumah menyebabkan ramai perempuan Minangkabau telah ketinggalan dalam bidang akademik, pendidikan, dan pekerjaan. Hal ini kerana, kaum perempuan tidak digalakkan keluar merantau terutamanya perempuan dalam masyarakat Minangkabau kerana tugas mereka selepas berkahwin adalah menjaga harta pusaka yang diusahakan oleh suaminya. 
b) Kemiskinan

Masalah kemiskinan dikenal pasti sebagai antara faktor pendorong seseorang keluar dari kampung halaman untuk merantau ke tempat lain. Hal ini kerana, taraf hidup yang rendah dan kesukaran membangunkan sumber ekonomi di tempat asal telah memaksa masyarakat untuk keluar bermigrasi. Menurut Katz (1989), punca kemiskinan adalah kerana kegagalan dasar kerajaan bagi mengubati punca kemiskinan dan membiarkan perkara ini berlarutan. Hal ini memaksa masyarakat melakukan aktiviti merantau sebagai satu inisiatif untuk memperbaiki dan meningkatkan taraf hidup mereka. Kemiskinan hidup yang dialami memaksa masyarakat keluar dari kampung halaman atau tempat asal untuk mencari sumber ekonomi yang lebih baik.

"Pada suatu hari, datang pula ke toko mereka seorang anak muda Jawa, bekas kuli kontrak pada sebuah perkebunan. Sebagaimana dengan keadaan kuli-kuli lain, datangnya ke Deli pun kerana tertipu pula......tiaptiap kedai orang yang dimasukinya dia melamar pekerjaan, jadi tukang cuci piring pun cukuplah, asal dia diberi makan."

(Di Bawah Lindungan Ka'bah, 2015, p. 46)

Sejajar dengan Teori Migrasi Everett S. Lee (1966) yang digunakan telah menyatakan faktor kemiskinan yang berada di tempat asal merupakan faktor pendorong kepada mereka untuk bermigrasi. Petikan di atas turut menyatakan bahawa terdapat watak Suyono yang merantau hingga ke Deli untuk meneruskan kehidupan kerana kemiskinan yang dialami semasa di tempat asal dan ingin membuat perubahan akan taraf hidup mereka agar menjadi lebih baik. Jelaslah, bahawa kemiskinan yang dihadapi oleh masyarakat di kampung halaman atau tempat asal telah memaksa mereka untuk bermigrasi.

2. Faktor Penarik Masyarakat Melayu Merantau dalam Teks Terpilih Karya Hamka

a) Keadaan Hidup yang Selesa

Faktor penarik yang dikaitkan dengan keadaan hidup yang selesa turut menyumbang berlakunya aktiviti merantau dengan kalangan masyarakat pada waktu ini. Mantra (2000) menyatakan kekuatan yang mendorong seseorang atau sekelompok masyarakat untuk berpindah ke tempat tujuan kerana kekuatan sentrifugal seperti keterbatasan pasaran kerja, atau fasiliti Pendidikan. Keselesaan migran selepas melakukan aktiviti migrasi adalah bergantung kepada tempat tinggal mereka di perantauan. Menurut Everett S. Lee (1966), perantau sewajarnya melakukan tinjauan awal dan terperinci mengenai tempat tinggal, tujuan dan destinasi perantau sebelum melakukan aktiviti migrasi agar tidak berlaku kesilapan dari sudut keselesaan di perantauan. 
Keadaan yang menyenangkan di tempat tujuan termasuk dari segi kestabilan politik dan kestabilan ekonomi telah mendorong segelintir masyarakat pergi merantau. Tambahan pula, jika tempat asal atau kampung halaman mereka berhadapan dengan masalah ketidakstabilan politik dan ekonomi yang berpanjangan. Hal ini diperkukuhkan lagi dengan pandangan Hezkiel Wodriusna (2017), iaitu faktor penarik dan kestabilan politik sesebuah negara memainkan peranan yang penting dan berkait rapat dgan ekonomi negara dan semasa proses migrasi antarabangsa.

"Kaum Kerabat Leman datanglah ke perantauan, seorang demi seorang, yang satu mendakwakan bahawa Leman mamaknya, yang seorang mengatakan bahawa Leman adalah saudara sepersukuan, yang lain mengatakan bertali darah."

(Di Bawah Lindungan Ka'bah, 2015, p. 45)

Keadaan politik dan ekonomi yang berlaku ini seiring dengan Teori Migrasi yang dibawa oleh Everett S. Lee (1966), iaitu terdapat faktor yang menjadi penarik kepada masyarakat untuk terus berhijrah ke tempat tujuan. Contohnya, dalam petikan di atas jelas menunjukkan saudaramara Leman mengambil peluang untuk berdampingan dengan Leman kerana dia sudah stabil dari sudut ekonominya. Keinginan merantau atas dasar untuk menikmati kestabilan ini masih boleh dilihat pada masa sekarang apabila terdapat ramai warga asing yang bekerja di Malaysia kerana kestabilan politik dan ekonominya (Hezkiel Wodriusna, 2017).

c) Tingkat Pendidikan

Tingkat pendidikan bermaksud satu proses pertumbuhan atas satu usaha bagi menciptakan keadaan atau situasi tertentu yang dikehendaki dalam sesebuah masyarakat atas tujuan pembentukan peribadi seseorang dalam menuju kedewasaan. Konsep merantau yang merupakan salah satu cara kaum lelaki mencari pengalaman agar mereka berguna semasa pulang ke tempat asal. Ketika menuntut ilmu di surau, mereka hanya diberikan ilmu keislaman, bela diri, adat-istiadat serta sebahagian kecil dari ilmu penting, iaitu ilmu ekonomi, pengetahuan alam atau dunia sosial. Keterbatasan ilmu yang memaksa masyarakat banyak merantau (Izatul Yazidah, 2017).

Pendidikan merupakan satu elemen penting dalam kehidupan masyarakat Minangkabau terutama dalam ilmu agama Islam. Hal in kerana, ada hukum menyebut "adat bersandi syarak, syarak bersandi kitabullah yang menyatakan mengenai masyarakat Minang mestilah menguasai pengetahuan dalam Islam. Oleh itu, pendidikan ilmu Islam yang terhad di Minang memaksa masyarakat Minang sendiri terutama dalam kalangan lelaki muda untuk keluar merantau (Komapos, 2019). Hal ini disokong oleh Muarif (2019) menyatakan bahawa keadaan kelihatan janggal apabila terdapat kaum lelaki muda Minang sendiri tidak keluar merantau di luar negeri dalam mencari ilmu. Migrasi atau dikenali 
sebagai merantau telah mendorong masyarakat dalam meningkatkan pendidikan atas tujuan yang berasas, iaitu untuk meningkatkan taraf kehidupan agar lebih selesa secara amnya.

"Saya tidak beberapa bulan setelah tamat sekolah, berangkat ke Padang Panjang, melanjutkan cita-cita ibu saya kerana kedermawanan Engku Haji Ja'far juga. Sekolah-sekolah agama yang di situ mudah sekali saya masuki, karena lebih dahulu saya telah mempelajari ilmu umum; saya hanya tinggal memperdalam pengertian dalam perkara agama saja, sehingga akhirnya salah seorang guru memberi pikiran...."

(Di Bawah Lindungan Ka’bah, 2015, p. 23)

Teori Migrasi yang dipelopori oleh Everett S. Lee jelas menyatakan mengenai faktor yang mendorong kepada tradisi merantau, iaitu faktor yang wujud di tempat tujuan atas dasar untuk meningkatkan pendidikan (Everett S. Lee, 1966). Teori ini bertepatan dengan petikan di atas, iaitu Hamid menjelaskan dia merantau ke luar negeri dalam dunia agama kerana ehsan Engku Ja'far. Hamid menjelaskan bahawa dia yang terus menyambung pelajaran selepas tamat sekolah membuktikan bahawa merantau hingga ke luar negeri adalah satu perjuangan dalam menuntut ilmu.

\section{Kesimpulan}

Kesimpulannya, tradisi merantau dalam masyarakat Melayu menerusi teks terpilih Hamka, iaitu Merantau Ke Deli dan Di Bawah Lindungan Ka'bah sememangnya mempunyai inti pati tradisi merantau dan sarat dengan budaya serta adat tinggalan zaman dahulukala. Kebijaksanaan pengarang Hamka dalam menyusun atur jalan cerita dalam karyanya hingga sarat dengan kandungan budaya, adat resam mampu menggambarkan realiti antaranya kandungan seperti konsep tradisi merantau, iaitu meninggalkan tempat asal, faktor penolak masyarakat Melayu merantau menerusi teks terpilih Hamka yang terdiri kepada jenis jantina dan kemiskinan serta faktor penarik masyarakat Melayu merantau menerusi teks terpilih Hamka, iaitu keadaan hidup yang selesa dan tingkat pendidikan.

Berdasarkan penelitian, Teori Migrasi Everett S. Lee sememangnya betepatan dengan analisis kajian, iaitu yang terdiri daripada faktor yang terdapat di tempat asal (Push Factors) dan faktor yang terdapat di tempat tujuan (Pull Factors). Rentetan itu, menerusi analisis kajian yang telah dilaksanakan memudahkan kajian ini dalam mencungkil tradisi merantau dalam teks terpilih Hamka, iaitu Merantau Ke Deli dan Di Bawah Lindungan Ka'bah. Pengaplikasian teori berkesan dijadikan panduan dan bahan rujukan kepada setiap penghasil karya. Teori ini mampu diguna pakai pada masa akan datang bagi mengkaji, mengkritik, menganalisis dan menilai hasil-hasil karya dengan lebih tepat, munasabah dan lengkap. 


\section{Rujukan}

Afif, F., \& Savaria. (2008). Kebudayaan Minangkabau dan Perantauan. Retrieved from http:// www.scribd.com/doc/50636800/16376462-Kebudayaan-Minangkabau-Dan-perantauan.

Akbar. (2011). Perspektif Merantau dalam Novel Dijemput Mamaknya Karya Hamka (Tinjauan Sosiologi Sastera). Retrieved from http://www.scholar.unand.ac.id/id/eprint/55854.

Akmal, S. Z., \& Nurwianti, F. (2012). Kekuatan karakter dan kebahagian pada suku Minang. Jurnal Ilmiah Psikologi, 3 (1).

Annisa Septia Sutamto. (2016). Dinamika Kepribadian Tokoh Utama Dalam Roman Di Bawah Lindungan Ka'bah Karangan Hamka dengan Senario Filem Di Bawah Lindungan Ka'bah Karya Titien Wattimena dan Armantono (Suatu Kajian Psikologi Sastera). Tesis Sarjana Pendidikan, Fakultas Bahasa dan Seni, Universitas Negeri Jakarta.

Azri Shaharudin. (1996). Merantau : Pola migrasi imigran Indonesia keturunan Minangkabau ke Malaysia Retrieved from http://malaycivilization.com.my/omeka/files/original/ b8023e0a0806aeb076.

Dwi Putri Rahmalia. (2020). Budaya Merantau Perempuan Minangkabau. Retrieved from http:// jom.unri.ac.id/index.php/JOMFSIP/article/download/26585/25702.

Fadli Abdullah \& Md Sidin Ahmad Ishak. (2010). Kesan perkembangan teknologi terhadap industri penerbitan buku di Malaysia. Jurnal Pengajian Media Malaysia 15(2): 71-86.

Hamka. (2015). Di Bawah Lindungan Ka'bah. Batu Caves, Selangor: PTS Publishing House Sdn. Bhd.

Hamka. (2015). Merantau Ke Deli. Batu Caves, Selangor: PTS Publishing House Sdn. Bhd.

Hastuti, P. C., Thoyib, A., Troena, E. A., \& Setiawan, M (2015). The Minang entrepreneur characteristic. Procedia - Socia; and Behavioral Sciences, 211 (September),819-826. http://doi.org/10.1016/j.sbspro.2015.11.108.

Hezkiel Wodriusna. (2017). Migrasi Buruh Asing Ke Malaysia. http://www.researchgate.net/ publication/315456970_MIGRASI_BURUH_ASING_KE_MALAYSIA.

Izatul Yazidah. (2017). Pengaruh Tingkat Pendidikan, Budaya Merantau dan Agama Terhadap Kegiatan Berwirausaha Rumah Makan Padang Kelurahan Pagar Dewan Kota Bengkulu. http://repository.iainbengkulu.ac.id/437/1/Iza\%20Tulyazidah.pdf.

Kamus Bahasa Indonesia Online. (2011). Retrieved from http:kamusbahasaindonesia.org/ merantau.

Kassim, f., \& Yaacob, N. (2018). Tradisi "Merantau” masyarakat Melayu bBerdasarkan puisi tradisional (pantun). Jurnal Sains Sosial dan Kemanusiaan, 10(3), 123-135. Retrieved from http://ejournal.upsi.edu.my/index.php/PERS/article/view/1799.

Katz, M. B. (1989). The Undeserving Poor: From the War on Poverty to the War on Welfare. New York: Pantheon Book. 
Khazrin, M.T. (2001). Dinamika Adat dan Tradisi Merantau di Alam Melayu. Dalam Abdul Latif. A. B. (Ed.), Adat Melayu Serumpun (pp. 73-85). Melaka: Perbadanan Muzium Melaka.

Lee, E. (1966). A Theory of Migration. Demography, 3(1), 47-57. Retrieved from http://www.jstor. org/stable/2060063.

Mantra, Ida Bagoes. (2000). Demografi Umum. Yogyarkata: Pustaka Pelajar.

Marlina. (2018). Tradisi Merantau Masyarakat dalam 'Lelaki dan Tangkai Sapu'. Retrieved from http://sawerigading.kemdikbud.go.id/index.php/sawerigading/article/download/497/34.

Mitchell, J. Clyde. (1961). The Causes of Labour Migration in Migrant Labour in Africa South of the Sahara. Abidjan, CCTA.

Muarif. (2009). Rahasia Sukses Orang Minang di Perantauan. Yogyarkata: ～Grepublishing.

Muhammad Takari, A. Zaidan B.S \& Fadlin Muhammad DJa'far. (2012). Sejarah Kesultanan Deli dan Peradaban Masyarakat. Medan: USU PRESS Bekerjasama dengan Kesultanan Deli.

Naim M. (1984). Merantau Pola Migrasi Suku Minangkabau. Yogjyakarta: Gadja Mada University Press.

Naim, Mochtar. (2013). Merantau Pola Migrasi Suku Minangkabau. Jakarta: Raja Grafindo Persada.

Nazarudin Zainun, Rahimah A. Hamid, \& Mohd Kipli Abdul Rahman. Kearifan Tempatan: Pengalaman Nusantara, Jilid 1. Minden, Pulau Pinang: Universiti Sains Malaysia.

Nor Ermawati Hussain, Norehan Abdullah \& Hussin Abdullah. (2015). Hubungan Migrasi Dalaman dengan Faktor-Faktor Penarik: Kajian Kes di Malaysia. Retrieved from http:/www.ukm.my/ fep/jem/pdf/2015-49(2)/jeko_49(2)-10.

Othman Puteh. (1998). Novel Remaja Malaysia: Perspektif Sejarah, Perkembangan, dan Tema. Dewan Sastera, pp. 7-11.

Pardi. (2019). Citra perempuan Jawa dalam novel Merantau ke Deli karya Hamka. Wahana Inovasi. Vol. 8, No 1.

Tsuyoshi Kato. (1989). Nasab ibu dan merantau. Kuala Lumpur: Dewan Bahasa dan Pustaka. 